\title{
Lithium-Associated Hypercalcemia: Pathophysiology, Prevalence, Management
}

\author{
Adrian D. Meehan ${ }^{1} \cdot$ Ruzan Udumyan ${ }^{2} \cdot$ Mathias Kardell $^{3} \cdot$ Mikael Landén $^{3} \cdot$ \\ Johannes Järhult ${ }^{4} \cdot$ Göran Wallin ${ }^{5}$
}

Published online: 19 December 2017

(C) The Author(s) 2017. This article is an open access publication

\begin{abstract}
Background Lithium-associated hypercalcemia (LAH) is an ill-defined endocrinopathy. The aim of the present study was to determine the prevalence of hypercalcemia in a cohort of bipolar patients (BP) with and without concomitant lithium treatment and to study surgical outcomes for lithium-associated hyperparathyroidism.

Methods Retrospective data, including laboratory results, surgical outcomes and medications, were collected from 313 BP treated with lithium from two psychiatric outpatient units in central Sweden. In addition, data were collected from $148 \mathrm{BP}$ without lithium and a randomly selected control population of 102 individuals. Logistic regression was used to compare odds of hypercalcemia in these respective populations.

Results The prevalence of lithium-associated hypercalcemia was $26 \%$. Mild hypercalcemia was detected in 87 out of 563 study participants. The odds of hypercalcemia were significantly higher in BP with lithium treatment compared with BP unexposed to lithium (adjusted OR $13.45 ; 95 \%$ CI $3.09,58.55 ; p=0.001$ ). No significant difference was detected between BP without lithium and control population (adjusted OR 2.40; 95\% CI 0.38, 15.41; $p=0.355$ ). Seven BP with lithium underwent surgery where an average of two parathyroid glands was removed. Parathyroid hyperplasia was present in four patients $(57 \%)$ at the initial operation. One patient had persistent disease after the initial operation, and six patients had recurrent disease at follow-up time which was on average 10 years.

Conclusion The high prevalence of LAH justifies the regular monitoring of calcium homeostasis, particularly in high-risk groups. If surgery is necessary, bilateral neck exploration should be considered in patients on chronic lithium treatment. Prospective studies are needed.
\end{abstract}

Adrian D. Meehan

adrian.meehan@regionorebrolan.se

1 Department of Geriatrics, Faculty of Medicine and Health, Örebro University, 70185 Örebro, Sweden

2 Clinical Epidemiology and Biostatistics, School of Medical Sciences, Örebro University Hospital, Örebro, Sweden

3 Section of Psychiatry and Neurochemistry, The Sahlgrenska Academy at University of Gothenburg, Sahlgrenska University Hospital, Gothenburg, Sweden

4 Department of Surgery, Ryhov Hospital, Jönköping, Sweden

5 Department of Surgery, Faculty of Medicine and Health, Örebro University, Örebro, Sweden

$\begin{array}{ll}\text { Abbreviations } \\ \text { BNE } & \text { Bilateral neck exploration } \\ \text { BPD } & \text { Bipolar disorder } \\ \text { cAMP } & \text { Cyclic adenosine monophosphate } \\ \text { CaSR } & \text { Calcium-sensitive receptors } \\ \text { FNE } & \text { Focused neck exploration } \\ \text { GAF } & \text { Global assessment of function } \\ \text { HPT } & \text { Hyperparathyroidism } \\ \text { iCa } & \text { Ionised calcium } \\ \text { LAH } & \text { Lithium-associated hypercalcemia } \\ \text { LHPT } & \text { Lithium-associated hyperparathyroidism } \\ \text { MGD } & \text { Multiglandular disease } \\ \text { pHPT } & \text { Primary (sporadic) hyperparathyroidism }\end{array}$


PTH Parathyroid hormone/parathormone

SBP St. Göran's Bipolar Project

SGD Single gland disease

TCa Total calcium

$\mathrm{TCa}_{\text {corr }}$ "Corrected" total calcium

\section{Introduction}

\section{Historic background}

Lithium has been used for a wide variety of ailments since the nineteenth century [1]. However, it was not until the illustrative case presentations of Cade [2] in 1949, and more convincingly with the work of Schou [3] in what may have been the first randomised study in psychiatry, that lithium became a more widely accepted medication in the treatment of mania in patients with bipolar disorder (BPD), previously known as manic depression. Organic disturbances associated with lithium salts were first documented by Garfinkel et al. [4] in 1973 who presented cases of both hypothyroidism and hyperparathyroidism in patients with concurrent lithium treatment. Since then, a series of articles have confirmed these initial observations. Studies concerning lithium and hypercalcemia are overwhelmingly retrospective in design and are limited in number (PubMed search with the words lithium AND hypercalcemia in January 2017 revealed only 139 articles). Lithium-associated hypercalcemia (LAH) is generally recognised as a prevailing side effect of lithium so long as treatment is necessary [5]. Lithium remains the golden standard for BPD, proving efficacious in the treatment of mania, as supplementary treatment for resistant depression and even reported as having anti-suicidal effects [6,7]. Lithium is frequently prescribed as a chronic medication and is in most cases lifelong thus necessitating the regular monitoring of calcium homeostasis; clinically, this has not been done systematically, where the focus of regular blood work-ups has been lithium concentration, thyroid and kidney function. It has been suggested that individuals with BPD may have genetically modified calcium receptors, potentially leading to altered calcium levels [8]. Additionally, there exists controversy concerning the histopathological background and appropriate surgical strategy of lithium-treated patients who have developed biochemical signs of hyperparathyroidism $[9,10]$.

\section{Aims of the study}

The aim of the present study is to determine the prevalence of hypercalcemia in bipolar patients with ongoing lithium treatment and compare this firstly to bipolar patients without lithium treatment and secondly to a randomly selected control population. A secondary aim is to study the long-term results of surgery for lithium-associated hyperparathyroidism (LHPT).

\section{Materials and methods}

The patients investigated in this study come from three separate research populations (Fig. 1). The 313 bipolar patients with ongoing lithium treatment were recruited as part of a prevalence study conducted between October 2012 and March 2014. These patients attended one of the affective outpatient units in either Jönköping County or Örebro County, Sweden. These two socio-economically similar counties, located in central Sweden, have about 460,000 residents, which is approximately $4.5 \%$ of the Swedish population. Patients' medical records were examined for all relevant information pertaining to parathyroid pathology including diagnoses, biochemistry, any possible surgery, and ongoing medication. All operations were performed by experienced endocrine surgeons. The choice and extent of surgery was at the surgeon's discretion since no uniform policy exists.

The second population, bipolar disorder without concomitant lithium treatment, were recruited from a research project called the St. Göran's Bipolar Project (SBP) led by one of the authors (ML) [11]. The project aims at further understanding the neurobiological mechanisms of mood disorders and started in October 2005. Regular follow-ups occur annually. Individuals were recruited from the bipolar outpatient unit at the Northern Stockholm Psychiatric Clinic, Stockholm, Sweden, with a catchment area of approximately 300,000 residents. According to available records, none of these patients have previously medicated with lithium.

A third population-based control group was randomly selected by Statistics Sweden (SCB) [12]. Individuals were contacted by post and fourteen per cent of those contacted agreed to participate as volunteers, and this level of participation is, according to SCB, comparable to similar studies. For these two latter populations, variables such as biochemical status pertinent to calcium homeostasis, relevant details about somatic disease and current medication were retrieved from the SBP study's database. 


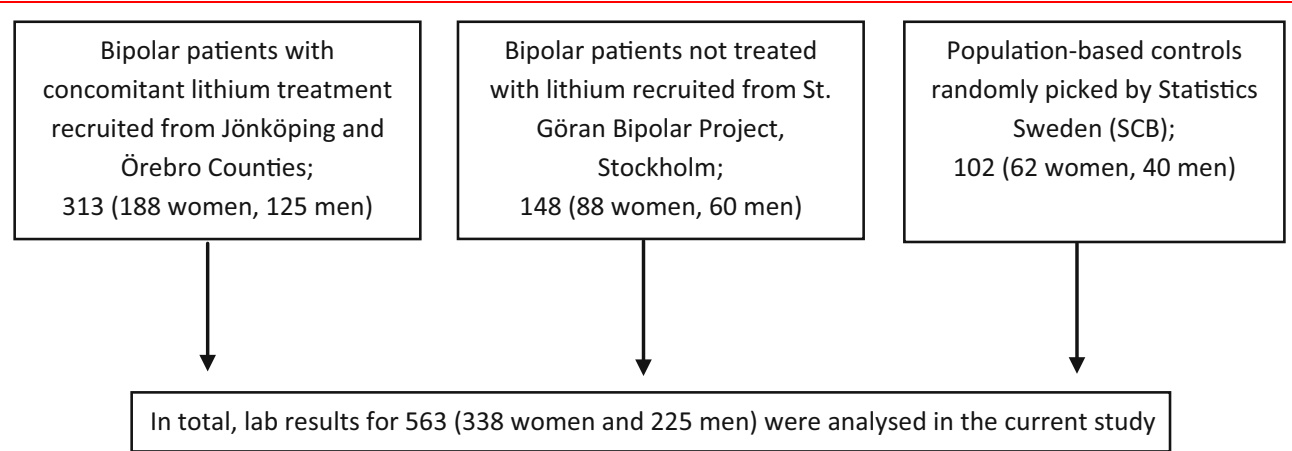

Fig. 1 Consort diagram for patient recruitment

\section{Assessment of hypercalcemia}

Data available for the assessment of hypercalcemia included total and corrected total calcium, creatinine and, where possible, parathormone. Parathormone was only available for bipolar patients with lithium (Table 1). Vitamin-D status was available in so few that comparison was not viable, and therefore abandoned. In addition, current medication was noted and classified according to whether the substance was a mood-stabiliser, central stimulants, antidepressant, anxiolytic, antipsychotic, anxiolytic other than benzodiazepines, and "other" medications most often pertaining to somatic disorders such as hypertension. Hypercalcemia was defined as average total calcium, $\mathrm{TCa} \geq 2.50 \mathrm{mmol} / \mathrm{l}$ according to national guidelines.

Table 1 Demographic and clinical variables, including the use of psychiatric and non-psychiatric medications, of study groups

\begin{tabular}{|c|c|c|c|c|c|}
\hline Variables & $\begin{array}{l}\text { Bipolar with lithium } \\
(n=313)\end{array}$ & $\begin{array}{l}\text { Bipolar without } \\
\text { lithium }(n=137)\end{array}$ & $\begin{array}{l}\text { Control population } \\
(n=102)\end{array}$ & $\begin{array}{l}\text { Total population } \\
(n=552)\end{array}$ & $p$ value* \\
\hline Female, $n(\%)$ & $188(60)$ & $88(60)$ & $62(61)$ & $338(60)$ & 0.989 \\
\hline Age, median years (range) & $57(19-92)$ & $35(18-74)$ & $34(21-75)$ & $48(18-92)$ & $\leq 0.001$ \\
\hline $\begin{array}{l}\text { Calcium mmol/l, median (range) (ref: } \\
2.10-2.50 \text { ) }\end{array}$ & $2.43(2.17-2.86)$ & $2.29(2.05-2.53)$ & $2.26(2.05-2.56)$ & $2.38(2.05-2.86)$ & $\leq 0.001$ \\
\hline PTH ng/l, median (range) (ref: $10-73)^{€}$ & $65(22-305)$ & $\mathrm{n} / \mathrm{a}^{\S}$ & $\mathrm{n} / \mathrm{a}$ & - & - \\
\hline $\begin{array}{l}\text { Creatinine } \mu \mathrm{mol} / \mathrm{l} \text {, median (range) (ref: 우 } \\
\quad 45-90, \sigma^{\uparrow} 60-105 \text { ) }\end{array}$ & $77(46-139)$ & $67(39-140)$ & $69(45-100)$ & $73(39-140)$ & $\leq 0.001$ \\
\hline $\begin{array}{l}\text { Hypercalcemia, } \geq 2 \text { episodes of } \\
2.50 \mathrm{mmol} / 1 \text { (\% of subsample })\end{array}$ & $82(26.2)$ & $2(1.4)$ & $3(2.9)$ & $87(15.5)$ & $\leq 0.001$ \\
\hline Pathological TSH, $n(\%)$ & $115(36.7)$ & 27 (19.7) & $5(4.9)$ & 147 (26.6) & $\leq 0.001$ \\
\hline GAF-symptom scale, median (range) ${ }^{\#}$ & $65(25-97)$ & $65(45-85)$ & $80(60-92)$ & $70(25-97)$ & $\leq 0.001$ \\
\hline $\begin{array}{l}\text { Duration of mood-stabilizing therapy, } \\
\text { median years (range) }\end{array}$ & $14(2-44)$ & $12(1-33)$ & - & - & 0.115 \\
\hline \multicolumn{6}{|l|}{ Use of medications } \\
\hline Levothyroxine, $n(\%)$ & $89(28.4)$ & $9(6.6)$ & $1(1.0)$ & $99(17.9)$ & $\leq 0.001$ \\
\hline Antidepressants, $n(\%)$ & $142(45.4)$ & $39(28.5)$ & $1(1.0)$ & $182(33.0)$ & $\leq 0.001$ \\
\hline Antipsychotics, $n(\%)$ & $105(33.5)$ & 27 (19.7) & $0(0.0)$ & $132(23.9)$ & $\leq 0.001$ \\
\hline Anxiolytics, $n(\%)$ & $49(15.7)$ & $22(16.1)$ & $0(0.0)$ & $71(12.9)$ & $\leq 0.001$ \\
\hline "Non-psychiatric" medications, $n(\%)$ & $207(66.1)$ & $47(34.3)$ & $41(40.2)$ & $295(53.4)$ & $\leq 0.001$ \\
\hline
\end{tabular}

* $p$ values are from a Chi-square test for categorical variables and from a median test for continuous variables

${ }^{€}$ Values available for 234 participants

$\S_{\mathrm{n}} / \mathrm{a}=$ not available

${ }^{\#}$ Values were available for 403 participants in this analysis

${ }^{\text {x} I n f o r m a t i o n ~ w a s ~ a v a i l a b l e ~ f o r ~} 176$ participants (39\%): 100 participants with BPD with lithium and 76 without lithium 


\section{Statistical analysis}

Descriptive statistics included frequencies (percentages) and median values (ranges). Individuals with hypercalcemia were compared with those without hypercalcemia using Chi-square test (for categorical measures), and a nonparametric test on the equality of medians (for nonnormally distributed continuous measures). The same tests were used to compare the distribution of the study covariates by the study groups (BP with lithium, BP without lithium and the control population). Unadjusted and adjusted logistic regression models compared odds of hypercalcemia in bipolar patients with ongoing lithium treatment as well as in a randomly selected control population with the corresponding odds in bipolar patients without lithium treatment.

The form of the relationship between the log odds of the hypercalcemia and continuous measures was explored using locally weighted scatterplot smoothing (LOWESS) methods, restricted cubic splines, as well as multivariable fractional polynomial methods. This analysis indicated a linear relationship with the log odds of hypercalcemia for age, GAF symptom, GAF function and creatinine. The statistical software used was Stata version 12/SE for Windows (StataCorp, College Station, Texas). Tests were two-sided, and statistical significance was defined as $p<0.05$ and $95 \%$ confidence intervals that do not include 1.00 .

\section{Ethics}

The approval for the collection of medical data and the completion of this study was given by the Central Ethics Review Board at the University of Uppsala, Sweden (Dnr 2011/428).

\section{Results}

The study population comprised 563 individuals with measured total calcium (Fig. 1). In comparison with bipolar without lithium (BWOL), the group bipolar with lithium (BWL) had statistically higher values of calcium, with a median $\mathrm{TCa}=2.43 \mathrm{mmol} / \mathrm{l}$ (range $=2.17-2.86$ ) (Table 1, Fig. 2). PTH was only available for BWL with a median of $65 \mathrm{ng} / \mathrm{l}(22-305)$ being reported. The prevalence of hypercalcemia was $15.8 \%$ in the whole group, though $26 \%$ in BWL. In addition, a disproportionate and significant proportion of BWL had had pathological thyroid values $(p=\leq 0.001)$ and medicated with levothyroxine $(p=\leq 0.001)$. The use of antidepressants, antipsychotics, sedatives and other "non-psychiatric" medications was more common in the BWL group (Table 1). In the group identified with hypercalcemia (Table 2), 94.3\% were BWL, $67 \%$ were female and had a median age of 64 years. Concomitant lithium treatment (adjusted OR 13.45; 95\% CI $3.09,58.55 ; p=0.001$ ) as well as older age and gender was associated with increased odds of hypercalcemia, whereas antidepressant use was associated with reduced odds (Table 3). BWL and BWOL scored lower values in the GAF instrument but in neither the unadjusted (Table 2) nor the adjusted analysis (OR 1.01 (95\% CI 0.98, 1.03)) was the GAF instrument associated with hypercalcemia (in a subgroup analysis of 403 people).

Bilateral neck exploration was performed in seven surgical cases (Table 4). Four women and three men were operated with a mean age of 60 years (range 46-74 years) after having medicated with lithium for 25 years (range 14-36 years). The histopathological diagnosis was hyperplasia in four patients at the initial operation with an average of two glands removed. One patient (case 5) with

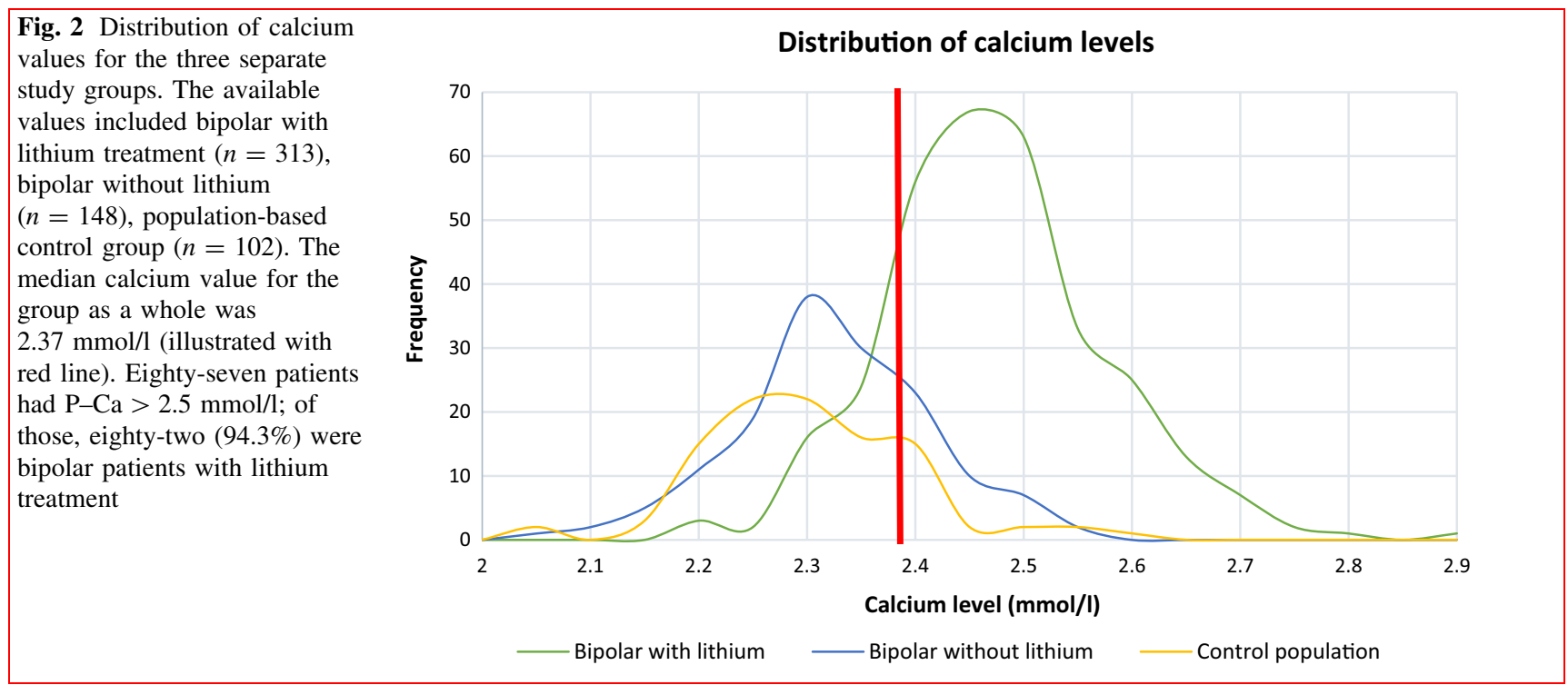


Table 2 Characteristics of study population according to calcium homeostasis

\begin{tabular}{|c|c|c|c|c|}
\hline Variables & $\begin{array}{l}\text { Hypercalcemia } \\
(n=87)\end{array}$ & $\begin{array}{l}\text { Normocalcemic } \\
(n=465)\end{array}$ & $\begin{array}{l}\text { Total population } \\
(n=552)\end{array}$ & $p$ value* \\
\hline \multicolumn{5}{|l|}{ Study groups } \\
\hline Bipolar with lithium, $n(\%)$ & $82(94.3)$ & $231(49.7)$ & $313(56.7)$ & \multirow[t]{3}{*}{$\leq 0.001$} \\
\hline Bipolar without lithium, $n(\%)$ & $2(2.3)$ & $135(29.0)$ & $137(24.8)$ & \\
\hline Control population, $n(\%)$ & $3(3.4)$ & $99(21.3)$ & $102(18.5)$ & \\
\hline Female, $n(\%)$ & $67(77.0)$ & $266(57.2)$ & $333(60.3)$ & $\leq 0.001$ \\
\hline Age, median years (range) & $64(24-90)$ & $45(18-92)$ & $47(18-92)$ & $\leq 0.001$ \\
\hline Calcium mmol/l, median (range) (ref: $2.10-2.50$ ) & $2.57(2.50-2.86)$ & $2.36(2.05-2.50)$ & $2.38(2.05-2.86)$ & $\leq 0.001$ \\
\hline $\begin{array}{l}\text { Creatinine } \mu \mathrm{mol} / 1 \text {, median (range) (ref: } \subsetneq \text { }+45-90, \hat{0} \\
\quad 60-105 \text { ) }\end{array}$ & $78(45-130)$ & $72(39-140)$ & $73(39-140)$ & 0.161 \\
\hline Pathological TSH, $n(\%)$ & $42(48.3)$ & $105(22.6)$ & $147(26.6)$ & $\leq 0.001$ \\
\hline GAF-symptom scale, median (IQR) ${ }^{\#}$ & $68(53-75)$ & $70(60-80)$ & $70(60-78)$ & 0.245 \\
\hline \multicolumn{5}{|l|}{ Use of medications } \\
\hline Levothyroxine, $n(\%)$ & $35(40.2)$ & $64(13.8)$ & $99(17.9)$ & $\leq 0.001$ \\
\hline Antidepressants, $n(\%)$ & $25(28.7)$ & $157(33.8)$ & $182(33.0)$ & 0.360 \\
\hline Antipsychotics, $n(\%)$ & $34(39.1)$ & $98(21.1)$ & $132(23.9)$ & $\leq 0.001$ \\
\hline Anxiolytics, $n(\%)$ & $17(19.5)$ & 54 (11.6) & $71(12.9)$ & 0.043 \\
\hline "Non-psychiatric" medications, $n(\%)$ & $66(75.9)$ & $229(49.2)$ & $295(53.4)$ & $\leq 0.001$ \\
\hline
\end{tabular}

* $p$ values are from a Chi-square test for categorical variables and from a median test for continuous variables

"Values were available for 403 participants in this analysis

Table 3 Multivariable analysis comparing hypercalcemia in bipolar patients without concomitant lithium treatment with bipolar patients with lithium and to a control population

\begin{tabular}{|c|c|c|c|c|}
\hline & Unadjusted OR (95\% CI) & $p$ value & Adjusted OR (95\% CI) & $p$ value \\
\hline \multicolumn{5}{|l|}{ Study groups ${ }^{\mathrm{a}}$} \\
\hline Bipolar without lithium & 1 (ref) & & 1 (ref) & \\
\hline Bipolar with lithium & $23.96(5.80,99.00)$ & $\leq 0.001$ & $13.45(3.09,58.55)$ & 0.001 \\
\hline Control population & $2.05(0.36,12.47)$ & 0.438 & $2.40(0.38,15.41)$ & 0.355 \\
\hline Age & - & & $1.04(1.02,1.06)$ & $\leq 0.001$ \\
\hline Sex & - & & $0.38(0.19,0.77)$ & 0.007 \\
\hline Creatinine & - & & $1.01(0.99,1.03)$ & 0.489 \\
\hline Pathological TSH & - & & $1.30(0.63,2.69)$ & 0.477 \\
\hline Levothyroxine & - & & $1.03(0.46,2.28)$ & 0.945 \\
\hline Antidepressants & - & & $0.38(0.21,0.67)$ & 0.001 \\
\hline Antipsychotics & - & & $1.88(1.04,3.04)$ & 0.036 \\
\hline Anxiolytics & - & & $1.66(0.80,3.45)$ & 0.174 \\
\hline "Non-psychiatric" medications & - & & $1.45(0.75,2.79)$ & 0.273 \\
\hline
\end{tabular}

${ }^{\mathrm{a}}$ Complete values were available for 552 individuals

lipoadenoma had persistent hypercalcemia post-operatively, was later re-operated with extirpation of a further two parathyroid glands and was normocalcemic at latest follow-up. All other patients had recurrent disease. The average follow-up was 10 years (range 5-12 years).

\section{Discussion}

We studied hypercalcemia in bipolar disorder. The prevalence of hypercalcemia in the entire study population is $15.5 \%$, with hypercalcemia remaining strongly associated with lithium treatment, even when adjusted for 


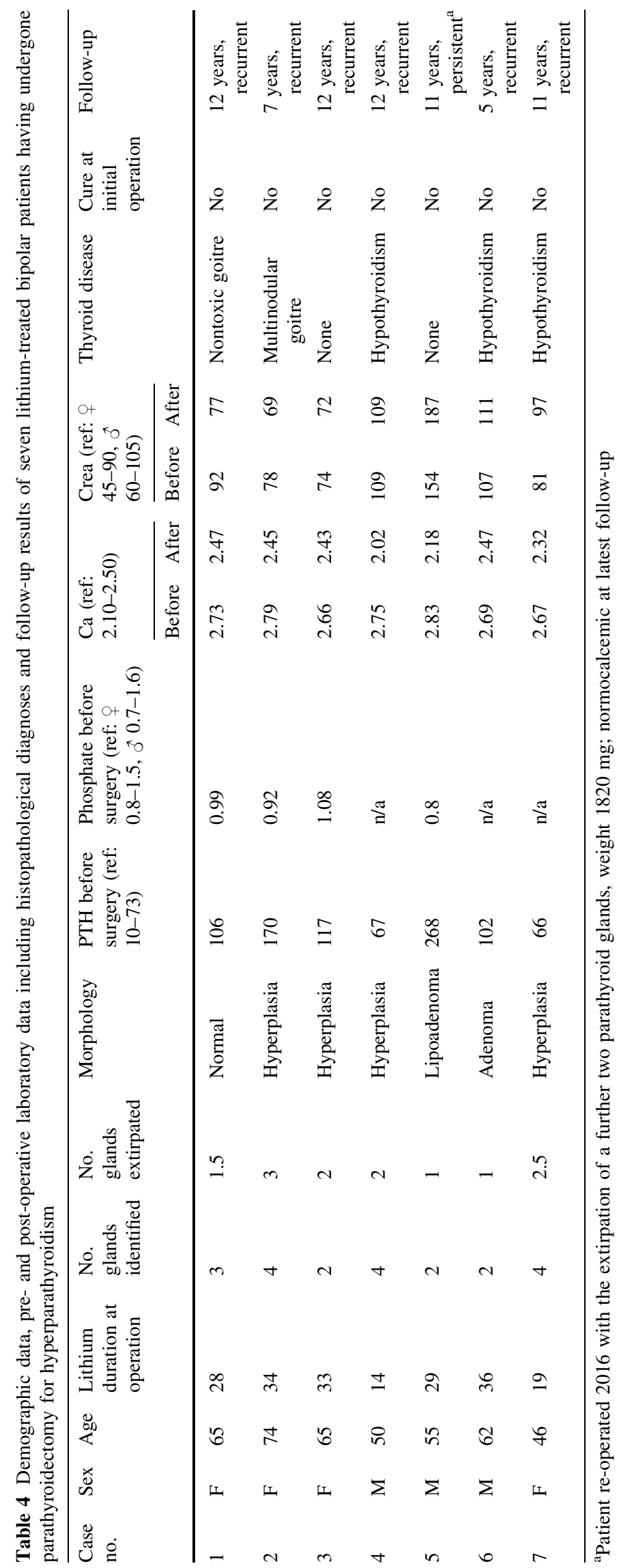


sociodemographic factors and medications (Table 3). This study demonstrates that a causal relationship between lithium treatment and the development of hypercalcemia may be presumed, though amid the plethora of possible mechanisms of action, the exact mechanism in the individual is difficult to ascertain. While polypharmacy, which was higher in the bipolar patients with lithium, may at the clinical level have bearing on the occurrence of hypercalcemia, it does not explain the statistically higher levels of calcium at group level. In addition, all seven lithiumtreated bipolar patients having undergone parathyroidectomy for LAH were not cured at the initial operation; one patient had persistent disease and six patients showed clear biochemical signs of recurrent disease at follow-up (Table 4).

\section{How common is LAH?}

Primary hyperparathyroidism is the third most common endocrine condition with a prevalence of approximately $0.5 \%$ in the general population, rising to $2-3 \%$ in postmenopausal women [12]. LAH is characterised by mildly elevated calcium levels (Fig. 2), which occur chronically or intermittently [13, 14]. Despite numerous articles highlighting the credible association between lithium and the development of hypercalcemia, the monitoring of parathyroid function has only recently been included in the revised recommendations of NICE [15] and the International Society for Bipolar Disorder [16]. In the light of this paucity of clear national and international guidelines, monitoring of parathyroid function has in many cases been scarce and irregular. This has led to evident difficulties in determining a reliable incidence and prevalence of LAH. McKnight et al. [17] reveal the absolute risk of developing LHPT is $10 \%$, considerably higher than pHPT. Estimations of LAH or LHPT prevalence vary widely from 4.3 to $80 \%$, though this possibly reflects the dimensions of study populations [18-21]. The present study confirms previous observations that at least a quarter of lithium-treated patients have repeated disturbances in calcium homeostasis (Table 1).

\section{Pathological background to hypercalcemia during lithium-treatment}

Lithium is a mood stabilizer but the exact biochemical mechanism of action has yet to be fully elucidated. The lithium ion is thought to be active, particularly in signal transduction pathways at multiple sites. Two main pathways of mood-stabilizing action are proposed, namely the inhibition of inositol monophosphatase, IMPase (important for cell regulatory functions such as cell growth and apoptosis), and the inhibition glycogen synthase kinase,
GSK-3 (important for apoptosis) [22-24]. By inhibiting GSK-3, long-term plasticity and neurocellular protection and stability may be achieved [25].

These mechanisms may be involved in lithium's implicatory role in the development of hypercalcemia. Szalat et al. [26] explains lithium's involvement in the cascade leading to the inhibition of IMPase in parathyroid chief cells, resulting in intracellular changes in calcium levels and thereby parathyroid hormone (PTH) secretion. A widely accepted theory is that lithium interacts with the calcium-sensing receptor (CaSR), a ubiquitously expressed transmembrane G-protein-coupled cell surface receptor, which in turn leads to a so-called right-shift or set-point elevation of calcium concentrations in relation to PTH [27, 28]. Chief cells then react as if the extracellular concentration of calcium has decreased. Exactly how lithium interacts with CaSR is difficult to determine. Furthermore, increased direct secretion of PTH is thought to occur through the development of adenoma or hyperplasia; hypocalciuria likely arises through the inhibition of renal cyclic adenosine monophosphate (cAMP) [13, 29].

Lithium affects PTH secretion and thereby causes PTHdependent hypercalcemia, whereas the use of drugs such as thiazides (not uncommon in the elderly) and vitamin D can cause PTH-independent hypercalcemia.

The pathoanatomical diagnosis of LAH is a matter of some contention. Primary HPT is caused by a single adenoma in $85 \%$ of cases, with hyperplasia in $10-15 \%$ [30]. Lithium, through GSK-3 inhibition, contributes to irregular $\mathrm{Wnt} / \beta$-catenin signalling, believed to be significant for the development of parathyroid adenomas and hyperplasia [31]. Theoretically, lithium should exert an equal effect on all parathyroid glands [32]. Carchman et al. [9], however, state that there is no significantly increased risk for multiglandular disease (MGD) in lithium-treated patients. On the other hand, numerous studies present higher frequencies of MGD ranging from 25 to 83\% [10, 26, 33-37]. The surgical results in the present study further confirm these latter results with MGD occurring in five of seven patients $(70 \%)$ (Table 4). This has clear ramifications for the treatment and management of LAH.

\section{Management of LAH}

Four main strategies for management of LAH are available. Firstly, lithium may be discontinued, with calcium normalisation occurring in many though far from all cases [5]. Discontinuation may be difficult due to the serious risk of psychiatric deterioration. Secondly, careful surveillance may be an option, though the patient's clinical status must be observed vigilantly. Thirdly, calcimimetic therapy has been described as possible strategy for LHPT, especially if continued lithium treatment is necessary [38]. This strategy 
is even proposed by Szalat et al. [26], particularly for those not suitable for surgery. The fourth and final strategy is surgery, though debate exists as to the degree of radicality that should be executed [9, 10, 33-37].

Surgical management of LAH is influenced by whether the condition is considered to be primarily a single glandular disease (SGD) or multiglandular (MGD). Hitherto, studies give differing views as to whether bilateral neck exploration (BNE) or focused neck exploration (FNE) is the appropriate surgical strategy. The role of pre-operative localisation techniques, has not been conclusively established for patients with LHPT [39]. Lithium is considered an exacerbating factor that "de-masks" the predisposition for the development of an adenoma, and FNE is recommended [9, 40, 41]. Awad et al. [40], in a study population of 15, found only one patient with MGD. The authors of this study (ADM, GW, JJ), in material yet unpublished, have found that four (1.5\%) of 297 patients had elevated calcium levels $(>2.5 \mathrm{mmol} / \mathrm{l})$ before the initiation of lithium treatment. The possibility of two coexisting phenomena, i.e., lithium treatment and pHPT, without any causal relationship, has to be considered [42]. Nevertheless, most studies suggest the frequent occurrence of MGD $[10,26,34-36]$. Hundley et al. [10] further point out that the resection of a single gland increases the risk of disease recurrence. On the other hand, the risk of permanent hypoparathyroidism with more radical surgery, though low, is not negligible [37]. The present recommendations of the European Society of Endocrine Surgeons (ESES) suggest that a history of lithium treatment is a relative indication for BNE [29].

\section{What is the significance of the present findings?}

There currently exists a lack of systemization in the monitoring of parathyroid function in lithium-treated patients, which may reflect the lack of clear guidelines on both the national and international level. Regular monitoring, involving TCa, PTH and vitamin D, would potentially identify all patients with tendencies towards hypercalcemia, whereby appropriate action could be taken. Hypercalcemia in lithium-treated patients with BPD was not correlated with kidney function, and even moderate chronic kidney insufficiency proved to be statistically insignificant (Table 3). The significance of hypercalcemia for the lithium-treated individual is unclear [14]. The GAF instrument did indicate that individuals with lithium treatment scored lower on this assessment of psychosocial functioning (Tables 1, 2). It illustrates the difficulty in discerning and differentiating symptoms primarily related to bipolar disorder and those associated with hypercalcemia. No robust instruments exist to differentiate these two conditions, but the need is apparent. It is often thought that non-lithium-treated patients with mildly elevated calcium are "asymptomatic", often leading to "doctor's delay" [19]. Talpos et al. [43], using SF-36, reported dramatic improvements in quality of life for seemingly asymptomatic HPT patients undergoing parathyroidectomy, effects that remained 2 years post-operatively. This underlines the need to penetrate the patient's anamnesis in a structured way in that it may play an important role in deciphering indications for surgery for LAH patients.

A large percentage of lithium-treated patients may be at risk of developing hypercalcemia, but far from all [31]. Some patients can medicate with lithium for decades without, at any time, showing tendencies towards calcium elevation. The reason for this is unclear. In the present study, lithium treatment, age, gender and thyroid disease were strongly associated with the development of hypercalcemia, while studies even point to treatment duration and dosage as associated risk factors $[5,14,18,28]$. These factors should be considered in any assessment for surgery as they may prove important in deciding the extent of any eventual operation.

The question of surgical management of LAH needs to be explored further. Most cases presented here had MGD (Table 4), though on average only two parathyroid glands were removed. The extent of surgery at the initial operation may have importance for the risk of recurrence, particularly for patients continuing lithium medication. There exists a strong need for prospective randomized surgical studies to evaluate appropriate management strategies in relation to patient benefit. Prospective therapeutic studies are also needed, including the evaluation of calcimimetics.

\section{Study limitations}

This study has several limitations. It is cross-sectional and thereby bereft of information as to disease debut or how calcium homeostasis changes over time. Secondly, it is retrospective, which adds to the risk that the collected information is selective and incomplete. Thirdly, though we recommend monitoring PTH and vitamin D, we have not been able to collect PTH for all the subgroups and vitamin D for only a small number of individuals. Collection of this data would have strengthened any conclusions that are made.

\section{Conclusion}

Our study reveals that hypercalcemia is not associated with bipolar disorder but is a common, though underestimated, characteristic of lithium treatment. We believe this condition to be far more complicated than has been described earlier. We postulate that genetic factors, lithium duration and dosage, 
gender, other medications and pathologies may together or separately contribute to the development of this highly debated endocrinopathy. Bilateral neck exploration should be considered for those individuals able to undergo surgery.

\section{Compliance with ethical standards}

Conflict of interest All authors declare no conflict of interest.

Open Access This article is distributed under the terms of the Creative Commons Attribution 4.0 International License (http://crea tivecommons.org/licenses/by/4.0/), which permits unrestricted use, distribution, and reproduction in any medium, provided you give appropriate credit to the original author(s) and the source, provide a link to the Creative Commons license, and indicate if changes were made.

\section{References}

1. Shorter E (2009) The history of lithium therapy. Bipolar Disord 11:4-9

2. Cade JF (1949) Lithium salts in the treatment of psychotic excitement. Med J Aust 2:349-352

3. Schou M, Juel-Nielsen N, Strömgren E, Voldby H (1954) The treatment of manic psychoses by the administration of lithium salts. J Neurol Neurosurg Psychiatry 17:250-257

4. Garfinkel PE, Ezrin C, Stancer HC (1973) Hypothyroidism and hyperthyroidism associated with lithium. Lancet 2:331-332

5. Shapiro HI, Davis KA (2015) Hypercalcemia and "primary" hyperparathyroidism during lithium therapy. Am J Psychiatry 172(1):12-15

6. Burgess SSA, Geddes J, Hawton KKE, Taylor MJ, Townsend E, Jamison K, Goodwin G (2001) Lithium for maintenance treatment of mood disorders. Cochrane Database Systematic Rev. https://doi.org/10.1002/14651858.CD003013

7. Lewitzka U, Severus E, Bauer R, Ritter P, Muller-Oerlinghausen B, Bauer M (2015) The suicide prevention effect of lithium: more than 20 years of evidence-a narrative review. Int $\mathrm{J}$ Bipolar Disord 3:15. https://doi.org/10.1186/s40345-015-0032-2

8. Cross-Disorder Group of the Psychiatric Genomics Consortium, Smoller JW, Craddock N et al (2013) Identification of risk loci with shared effects on five major psychiatric disorders: a genomewide analysis. Lancet. 381:1371-1379

9. Carchman E, Ogilvie J, Holst J, Yim J, Carty S (2008) Appropriate surgical treatment of lithium-associated hyperparathyroidism. World J Surg 32:2195-2199. https://doi.org/10.1007/ s00268-008-9616-7

10. Hundley JC, Woodrum DT, Saunders BD, Doherty GM, Gauger PG (2005) Revisiting lithium-associated hyperparathyroidism in the era of intraoperative parathyroid hormone monitoring. Surgery 138:1027-1031

11. Rydén E, Thase ME, Stråht D, Åberg-Wistedt A, Bejerot S, Landén M (2009) A history of childhood attention-deficit hyperactivity disorder (ADHD) impacts clinical outcome in adult bipolar patients regardless of current ADHD. Acta Psychiatr Scand 120:239-246

12. Jakobsson J, Zetterberg H, Blennow K, Ekman CJ, Johansson AG, Landén M (2013) Altered concentrations of amyloid precursor protein metabolites in the cerebrospinal fluid of patients with bipolar disorder. Neuropsychopharmacology 38(4):664-672
13. Livingstone C, Rampes H (2006) Lithium: a review of its metabolic adverse affects. J Psychopharmacol 20:347-355

14. Meehan AD, Humble MB, Yazarloo P, Jarhult J, Wallin G (2015) The prevalence of lithium-associated hyperparathyroidism in a large Swedish population attending psychiatric outpatient units. J Clin Psychopharmacol 35:279-285

15. NICE clinical guideline 38. Bipolar disorder: the management of bipolar disorder in adults, children and adolescents, in primary and secondary care (2006)

16. Ng F, Oomen KM, Wilting I et al (2009) The International Society for Bipolar Disorder (ISBD) consensus guidelines for the safety monitoring of bipolar disorder treatments. Bipolar Disord 11:559-595

17. McKnight RF, Adida M, Budge K, Stockton S, Goodwin GM, Geddes JR (2012) Lithium toxicity profile: a systematic review and meta-analysis. Lancet 379:721-728

18. Lehmann SW, Lee J (2012) Lithium-associated hypercalcemia and hyperparathyroidism in the elderly: what do we know? J Affect Disord 146:151-157

19. Twigt BA, Houweling BM, Vriens MR et al (2013) Hypercalcemia in patients with bipolar disorder treated with lithium: a cross-sectional study. Int J Bipolar Disord 1:18

20. Albert U, De Cori D, Aguglia A, Barbaro F, Lanfranco F, Bogetto F, Maina G (2013) Lithium-associated hyperparathyroidism and hypercalcemia: a case-control cross-sectional study. J Affect Disord 151:786-790

21. Lally J, Lee B, McDonald C (2013) Prevalence of hypercalcaemia in patients on maintenance lithium therapy monitored in primary care. Ir Med J 106:15-17

22. Stahl SM (2011) Stahl's essential psychopharmacology: neuroscientific basis and practical applications. Cambridge University Press, New York

23. Jope RS (1999) Anti-bipolar therapy: mechanism of action of lithium. Mol Psychiatry 4(117):128

24. Belmaker RH, Agam G, Lenox RH (2007) Neurobiology and Pharmacotherapy of Bipolar Disorder. In: Sibley DR, Hanin I, Kuhar M, Skolnick P (eds) Handbook of contemporary neuropharmacology. Wiley, New York, pp 859-875

25. Brown KM, Tracy DK (2013) Lithium: the pharmacodynamic actions of the amazing ion. Ther Adv Psychopharmacol 3(3): $163-176$

26. Szalat A, Maze H, Freund HR (2009) Lithium-associated hyperparathyroidism: report of four cases and review of the literature. Eur J Endocrinol 160:317-323

27. Haden ST, Stoll AL, McCormick S, Scott J, El-Hajj Fuleihan G (1997) Alterations in parathyroid dynamics in lithium-treated subjects. J Clin Endocrinol Metab 82(9):2844-2848

28. Saunders BD, Saunders EF, Gauger PG (2009) Lithium therapy and hyperparathyroidism: an evidence-based assessment. World $\mathrm{J}$ Surg 33:2314-2323. https://doi.org/10.1007/s00268-009-9942-4

29. Barczynski M, Branstrom R, Dionigi G, Mihai R (2015) Sporadic multiple parathyroid gland disease-a consensus report of the European Society of Endocrine Surgeons (ESES). Langenbecks Arch Surg 400(8):887-905

30. Fraser WD (2009) Hyperparathyroidism. Lancet 374:145-158

31. Westin G, Bjorklund P, Akerstrom G (2009) Molecular genetics of parathyroid disease. World J Surg 33:2224-2233. https://doi. org/10.1007/s00268-009-0022-6

32. Meehan AD, Humble MB, Yazarloo P, Jarhult J, Wallin G (2016) Letter to editors: reply to comments from Dr Lozano et alconcerning the prevalence of lithium-associated hyperparathyroidism. J Clin Psychopharmacol 36(2):191-192

33. Järhult J, Ander S, Asking B, Jansson S, Meehan A, Kristoffersson A, Nordenström J (2010) Long-term results of surgery for lithium-associated hyperparathyroidism. Br J Surg 97:1680-1685 
34. Ballehaninna UK, Nguyen SM, Chamberlain RS (2011) Lithium associated hyperparathyroidism: an evidence based surgical approach. Surg Sci 2:468-475

35. Skandarajah AR, Palazzo FF, Henry JF (2011) Lithium-associated hyperparathyroidism: surgical strategies in the era of minimally invasive parathyroidectomy. World J Surg 35:2432-2439. https://doi.org/10.1007/s00268-011-1220-6

36. Marti JL, Yang CS, Carling T, Roman SA, Sosa JA, Donovan P, Guoth MS, Heller KS, Udelsman R (2012) Surgical approach and outcomes in patients with lithium-associated hyperparathyroidism. Ann Surg Oncol 19:3465-3471

37. Norlén O, Sidhu S, Sywak M, Delbridge L (2014) Long-term outcome after parathyroidectomy for lithium-induced hyperparathyroidism. Br J Surg 101:1252-1256

38. Gregoor PS, de Jong GMT (2007) Lithium hypercalcemia, hyperparathyroidism, and cinacalcet. Kidney Int 71:470

39. Khairallah W, Fawaz A, Brown EM, El-Hajj FG (2007) Hypercalcemia and diabetes insipidus in a patient previously treated with lithium. Nat Clin Pract Nephrol 3(7):397-404
40. Awad SS, Miskulin J, Thompson N (2003) Parathyroid adenomas versus four-gland hyperplasia as the cause of primary hyperparathyroidism in patients with prolonged lithium therapy. World J Surg 27:486-488. https://doi.org/10.1007/s00268-002-6824-4

41. McHenry CR, Rosen IB, Rotstein LE, Forbath N, Walfish PG (1990) Lithiumogenic disorders of the thyroid and parathyroid glands as surgical disease. Surgery 108:1001-1005

42. Nordenström J, Strigård K, Perbeck L, Willems J, BågedahlStrindlund M, Linder J (1992) Hyperparathyroidism associated with treatment of manic-depressive disorders by lithium. Eur J Surg 158:207-211

43. Talpos GB et al (2000) Randomized trial of parathyroidectomy in mild asymptomatic primary hyperparathyroidism: patient description and effects on the SF-36 health survey. Surgery 128(6):1013-1020 [discussion 1020-11] 